\title{
On the validity of lumped capacitance approaches for the numerical prediction of heat and mass transfer in desiccant airflow systems
}

\author{
C.R. Ruivo ${ }^{1}$, J.J. Costa*, A.R. Figueiredo \\ ADAI, Department of Mechanical Engineering, University of Coimbra, P 3030788 Coimbra, Portugal \\ Received 28 October 2005; accepted 28 January 2007 \\ Available online 3 April 2007
}

\begin{abstract}
In the present work, a detailed model of simultaneous heat and mass transfer through a desiccant micro-porous medium of a channel wall of compact heat and mass exchangers, such as desiccant wheels, was developed. The relevant phenomena considered by this model within the porous medium are surface diffusion of the adsorbed water, Knudsen diffusion of water vapour, heat conduction and the sorption process. A onedimensional formulation of this model is used to investigate the validity of two simplifying approaches based on the lumped-capacitance method. One consists of neglecting the transversal heat and mass transfer resistances within the porous medium, the other of cancelling only the thermal resistance.

Results are presented for a wide range of values of the layer thickness of the porous medium. It is concluded that the hypothesis of nullresistances in the cross direction is valid only for layer thicknesses lower than $0.1 \mathrm{~mm}$, approximately, while the approach based on the thermal lumped capacitance model is valid for layer thicknesses lower than $5 \mathrm{~mm}$. Finally, a dimensional analysis of interfacial balances leads to the conclusion that the Biot number for surface diffusion is several orders of magnitude higher than the corresponding thermal Biot number.
\end{abstract}

(c) 2007 Elsevier Masson SAS. All rights reserved.

Keywords: Adsorption; Desiccant layer; Lumped capacitance models; Heat and mass exchangers

\section{Introduction}

The study of the transport phenomena in desiccant airflow systems has been addressed in numerous research works, many of them concerning combined desiccant cooling and dehumidification, air filtering, air dehumidification and energy recovery processes (e.g., [1-16]).

A significant number of studies was carried out to predict the behaviour of air dehumidifying systems using simplified mathematical models (e.g., [17-27]). In most of them, the heat and mass transport phenomena occurring inside the porous desiccant medium are not described in a very detailed way, simplified approaches being adopted instead. Pseudo-gas-side controlled

\footnotetext{
* Corresponding author. Tel.: +351 239 790732; fax: +351 239790771.

E-mail addresses: cruivo@ualg.pt (C.R. Ruivo), jose.costa@dem.uc.pt (J.J. Costa).

1 Present address: Área Departamental de Engenharia Mecânica, Escola Superior de Tecnologia, Universidade do Algarve, Campus da Penha, 8005-139 Faro, Portugal.
}

models have been the most used models (e.g., [21]) based on fictitious overall heat and mass transfer coefficients when it is important to take into account the internal resistances in the desiccant. A single-blow test procedure for compact heat and mass transfer exchangers to evaluate those overall transfer coefficients is presented in [28]. An alternative to this approach consists in using the parabolic profile assumption, which validity was investigated in [29] and supports the rotary desiccant dehumidifier model used in [23].

The range of validity of such models can be investigated by using experimental techniques and by detailed numerical modelling. The adsorbate surface diffusion inside microporous media like silica gel is known to be a dominant mechanism [6]. Some studies concerning the use of correlations for solid-side mass diffusivity estimation are important references [30-33], but large discrepancies between experimental and theoretical values are observed [33].

The air stream behaviour and its interaction with the desiccant medium are also often treated in a simplified way, namely by assuming a fictitious bulk flow pattern, as well as fictitious 


\section{Nomenclature}

$B i_{\mathrm{h}} \quad$ Biot number for heat transfer

$B i_{\mathrm{K}} \quad$ Biot number for Knudsen diffusion

$B i_{\mathrm{m}} \quad$ Biot number for mass transfer

$B i_{\mathrm{S}} \quad$ Biot number for surface diffusion

$C_{\ell} \quad$ mass concentration of adsorbed water $\ldots . \mathrm{kg} \mathrm{m}^{-3}$

$C_{\ell}^{+} \quad$ dimensionless mass concentration of adsorbed water

$C_{\mathrm{v}} \quad$ vapour mass concentration of the gas mixture

inside the porous medium ............ $\mathrm{kg} \mathrm{m}^{-3}$

$C_{\mathrm{v}}^{+} \quad$ dimensionless vapour mass concentration of the gas mixture inside the porous medium

$C_{\mathrm{v}, \mathrm{f}} \quad$ vapour mass concentration in the airflow ....................... $\mathrm{kg} \mathrm{m}^{-3}$

$C_{\mathrm{v}, \mathrm{i}} \quad$ vapour mass concentration in the gas mixture at the interface ........................ $\mathrm{kg} \mathrm{m}^{-3}$

$c_{\mathrm{p}, \mathrm{f}} \quad$ specific heat of the air flow $\ldots \ldots \ldots \quad \mathrm{J} \mathrm{kg}^{-1}{ }^{\circ} \mathrm{C}^{-1}$

$\begin{array}{llll}c_{\mathrm{p}, \mathrm{p}} & \text { specific heat of porous medium } \ldots . . . & \mathrm{J} \mathrm{kg}^{-1}{ }^{\circ} \mathrm{C}^{-1}\end{array}$

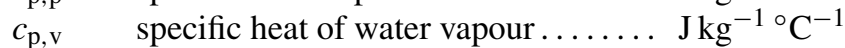

$D_{\mathrm{f}} \quad$ diffusion coefficient of water vapour in the

airflow ....................... $\mathrm{m}^{2} \mathrm{~s}^{-1}$

$D_{\mathrm{K}, \text { eff }} \quad$ effective coefficient of Knudsen

diffusion..................... $\mathrm{m}^{2} \mathrm{~s}^{-1}$

$D_{\mathrm{p}} \quad$ coefficient of water (mass) diffusion inside the

porous medium.................. $\mathrm{m}^{2} \mathrm{~s}^{-1}$

$D_{\mathrm{s}, \text { eff }}$ effective coefficient of surface diffusion

(of adsorbed water) ..................... $\mathrm{m}^{2} \mathrm{~s}^{-1}$

$d_{\text {hyd }} \quad$ hydraulic diameter $\ldots \ldots \ldots \ldots \ldots \ldots \ldots \ldots$

$h_{\text {ads }} \quad$ heat of adsorption .................. $\mathrm{J} \mathrm{kg}^{-1}$

$h_{\mathrm{h}} \quad$ convection heat transfer

coefficient.................. W m ${ }^{-2}{ }^{\circ} \mathrm{C}^{-1}$

$h_{\mathrm{fg}} \quad$ latent heat of vaporization $\ldots \ldots \ldots \ldots \ldots \mathrm{J} \mathrm{kg}^{-1}$

$h_{\ell} \quad$ enthalpy of liquid water $\ldots \ldots \ldots \ldots \ldots \mathrm{J} \mathrm{kg}^{-1}$

$h_{\ell}^{\prime} \quad$ enthalpy of adsorbed water $\ldots \ldots \ldots \ldots . \mathrm{J} \mathrm{kg}^{-1}$

$h_{\mathrm{m}} \quad$ convection mass transfer coefficient ....... $\mathrm{m} \mathrm{s}^{-1}$

$h_{\mathrm{v}} \quad$ enthalpy of vapour $\ldots \ldots \ldots \ldots \ldots \ldots \mathrm{J} \mathrm{kg}^{-1}$

$h_{\mathrm{w}}^{\prime} \quad$ heat of wetting $\ldots \ldots \ldots \ldots \ldots \ldots \ldots, \ldots \ldots \mathrm{J} \mathrm{kg}^{-1}$

$j_{\text {ads }} \quad$ adsorption rate per unit area of the

interface ................... $\mathrm{kg} \mathrm{s}^{-1} \mathrm{~m}^{-2}$

$j_{\text {app }}$ heat or mass convective flux predicted by the simplified model

$j_{\mathrm{h}} \quad$ convective heat flux $\ldots \ldots \ldots \ldots \ldots . \ldots \mathrm{W} \mathrm{m}^{-2}$

$j_{\mathrm{h}}^{+} \quad$ dimensionless heat conduction flux

$j_{\mathrm{h}, \text { ads }}^{+} \quad$ dimensionless heat generation/consumption rate per unit area of the interface

$j_{\mathrm{K}}^{+} \quad$ dimensionless Knudsen flux at the interface

$j_{\mathrm{m}} \quad$ convective mass flux ............. kg s s $\mathrm{m}^{-2}$

$j_{\text {ref }} \quad$ heat or mass convective flux predicted by the detailed model

$j_{\mathrm{s}}^{+} \quad$ dimensionless surface diffusion flux at the interface

Le Lewis number

$M_{\mathrm{v}} \quad$ molecular mass of water $\ldots \ldots \ldots \ldots \mathrm{kg} \mathrm{kmol}^{-1}$

$\mathrm{Nu} \quad$ Nusselt number

$p \quad$ pressure of the air-vapour mixture $\ldots . \ldots \ldots . . . \mathrm{Pa}$

$p_{\mathrm{v}} \quad$ partial pressure of water vapour........... Pa $p_{\mathrm{v}, \text { sat }} \quad$ saturation pressure of water vapour $\ldots \ldots \ldots . . \mathrm{Pa}$

$R_{\mathrm{gv}} \quad$ particular gas constant of the air-vapour

mixture .................... $\mathrm{J} \mathrm{kg}^{-1}{ }^{\circ} \mathrm{C}^{-1}$

$R_{\mathrm{V}} \quad$ particular gas constant of water

vapour.................... $\mathrm{J} \mathrm{kg}^{-1}{ }^{\circ} \mathrm{C}^{-1}$

average radius of pore volume occupied by the

gaseous phase $\ldots \ldots \ldots \ldots \ldots \ldots \ldots \ldots \ldots, m$

$S_{\text {ads }} \quad$ source-term in the energy conservation

equation (3) ................... W m ${ }^{-3}$

Sh Sherwood number

$S_{\mathrm{v}-\ell} \quad$ source-term in the mass conservation equations (1) and $(2) \ldots \ldots \ldots \ldots \ldots \ldots \ldots \ldots \ldots \ldots \ldots \ldots \mathrm{kg} \mathrm{s}^{-1} \mathrm{~m}^{-3}$

$s \quad$ thickness of the desiccant layer ..........m

$T \quad$ temperature....................... ${ }^{\circ} \mathrm{C}$

$\widetilde{T} \quad$ average temperature of the porous medium... ${ }^{\circ} \mathrm{C}$

$T_{\mathrm{i}} \quad$ temperature of the interface $\ldots \ldots \ldots \ldots \ldots,{ }^{\circ} \mathrm{C}$

$T_{\mathrm{f}} \quad$ temperature of the airflow $\ldots \ldots \ldots \ldots \ldots \ldots{ }^{\circ} \mathrm{C}$

$T_{0} \quad$ initial temperature in the porous medium ..... ${ }^{\circ} \mathrm{C}$

$t \quad$ time coordinate ..................... s

$t_{1} \quad$ time to the variable $\widetilde{X}_{\ell}$ predicted by the detailed model attain $90 \%$ of the maximum variation .... s water-vapour content of the gas mixture inside the porous medium (d.b.) .............. $\mathrm{kg} \mathrm{kg}^{-1}$

$\widetilde{w}_{\mathrm{v}} \quad$ average water-vapour content of the gas mixture in the porous medium (d.b.) ............ $\mathrm{kg} \mathrm{kg}^{-1}$

${\underset{\tilde{X}}{X}}_{\ell} \quad$ adsorbed water content (d.b.) $\ldots \ldots \ldots \ldots \quad \mathrm{kg} \mathrm{kg}^{-1}$

$\tilde{X}_{\ell} \quad$ average adsorbed water content in the porous medium (d.b.) .................. $\mathrm{kg} \mathrm{kg}^{-1}$

$X_{\ell, 0} \quad$ initial adsorbed water content in the porous medium ..................... $\mathrm{kg} \mathrm{kg}^{-1}$

$\tilde{X}_{\ell}^{+} \quad$ dimensionless average adsorbed water content in the porous medium

$y \quad$ spatial coordinate $\ldots \ldots \ldots \ldots \ldots \ldots \ldots \ldots$

Greek symbols

$\Delta \varepsilon \quad$ deviation between the evolutions of the convective heat or mass fluxes, with respect to the detailed model (Eq. (19))

$\varepsilon_{\mathrm{gv}} \quad$ volume fraction of the gaseous mixture within the porous medium

$\phi \quad$ generic variable, i.e., temperature, adsorbed water content or water-vapour content

$\Phi_{\mathrm{h}, \text { ads }}^{+}$ratio between the heat released in the phase change of the vapour flux convected to the interface, if the phase change were completely achieved, and the convection heat flux (Eq. (26a))

$\varphi_{\mathrm{v}} \quad$ vapour mass fraction of the gas mixture inside the porous medium................. $\mathrm{kg} \mathrm{kg}^{-1}$

$\varphi_{\mathrm{v}, \text { eq }} \quad$ vapour mass fraction of the gas mixture within the porous medium at equilibrium .......... $\mathrm{kg} \mathrm{kg}^{-1}$ $\varphi_{\mathrm{v}, \mathrm{f}} \quad$ vapour mass fraction in the airflow ...... $\mathrm{kg} \mathrm{kg}^{-1}$ $\varphi_{\mathrm{v}, \mathrm{i}} \quad$ vapour mass fraction of the gas mixture at the interface $\ldots \ldots \ldots \ldots \ldots \ldots \ldots \ldots \ldots \mathrm{kg} \mathrm{kg}^{-1}$ 


\begin{tabular}{|c|c|c|c|}
\hline$\lambda_{\mathrm{f}}$ & thermal conductivity of the airflow.. $\mathrm{W} \mathrm{m}^{-1}{ }^{\circ} \mathrm{C}^{-1}$ & + & dimensionless variable \\
\hline$\lambda_{\mathrm{p}}$ & $\begin{array}{l}\text { thermal conductivity of the porous } \\
\text { medium } \ldots \ldots \ldots \ldots \ldots \ldots \ldots \ldots \ldots \mathrm{W} \mathrm{m}^{-1}{ }^{\circ} \mathrm{C}^{-1}\end{array}$ & \multicolumn{2}{|c|}{ Subscripts } \\
\hline$\rho_{\mathrm{d}}^{*}$ & apparent density of the dry desiccant $\ldots \ldots \mathrm{kg} \mathrm{m}^{-3}$ & 0 & initial condition \\
\hline$\rho_{\mathrm{f}}$ & density of the airflow $\ldots \ldots \ldots \ldots \ldots \ldots \mathrm{kg} \mathrm{m}^{-3}$ & ads & relative to the adsorption phenomenon \\
\hline$\rho_{\mathrm{gv}}$ & $\begin{array}{l}\text { density of the fluid inside the porous } \\
\text { medium } \ldots \ldots \ldots \ldots \ldots \ldots \ldots \ldots \ldots \ldots \mathrm{kg} \mathrm{m}^{-3}\end{array}$ & $\begin{array}{l}\text { d } \\
\text { eff }\end{array}$ & $\begin{array}{l}\text { dry desiccant } \\
\text { effective quantity }\end{array}$ \\
\hline$\rho_{\mathrm{gv}}^{*}$ & apparent density of the gas mixture inside the & eq & $\begin{array}{l}\text { equilibrium conditions } \\
\text { airflow }\end{array}$ \\
\hline$\tau_{\ell}$ & $\begin{array}{l}\text { porous medium } \ldots \ldots \ldots \ldots \ldots \ldots \ldots \mathrm{kg} \mathrm{m}^{-3} \\
\text { tortuosity of the adsorbed water path within the } \\
\text { porous medium }\end{array}$ & $\begin{array}{l}\text { g } \\
\text { hv }\end{array}$ & $\begin{array}{l}\text { gaseous mixture (air-vapour) } \\
\text { heat }\end{array}$ \\
\hline$\tau_{\mathrm{gv}}$ & tortuosity of the water vapour path & $\mathrm{i}$ & solid-airflow interface \\
\hline$\psi$ & $\begin{array}{l}\text { relative pressure, i.e., ratio of the partial vapour } \\
\text { pressure to the saturation vapour pressure }\end{array}$ & $\begin{array}{l}\mathrm{m} \\
\mathrm{p} \\
\text { sat }\end{array}$ & $\begin{array}{l}\text { mass } \\
\text { porous medium } \\
\text { saturation condition }\end{array}$ \\
\hline Sup & ripts & st & steady-state condition \\
\hline$*$ & apparent density & $\mathrm{v}$ & water vapour \\
\hline ' & adsorbed water & $\ell$ & free liquid water or adsorbed water \\
\hline
\end{tabular}

heat and mass convection coefficients for the gas side. Concerning convection heat transfer, work was carried out to obtain values of the Nusselt number in corrugated ducts of compact desiccant matrixes by holographic interferometry [34] and by detailed numerical modelling of the airflow field $[35,36]$. The convection mass transfer can be estimated through the Sherwood number, this one being given by the analogy between heat and mass transfer characterized by $L e \approx 1$.

The experimental work on desiccant devices such as desiccant wheels has been focused on the validation of physical prediction models [8,37-40], the development of simplified models based on experimental data correlations [40-42] and the performance characterization by carrying out numerous experiments under various operating conditions [43,44].

Several studies of partial or complete solid desiccant systems for air conditioning have been conducted, mainly supported on experimental results $[45,46]$ or using mathematical modelling with the behaviour of the desiccant device taken from proper laboratory experiments [47], manufacturer's performance data [48] or specific modelling software [49-51].

When advanced numerical methods are used, solving the complete set of differential transport equations, a number of critical issues still remains, such as the lack of suitable functions to describe the variation of the porous medium properties $[8,42,52,53]$ and the complexity of numerically solving the intrinsically coupled phenomena within the porous desiccant solid and the great time consumption of computational calculations [23]. An additional delicate question consists of accurately representing the solid-fluid interface phenomena [11,15]. Nevertheless, advanced mathematical models-including surface diffusion of the adsorbed phase, Knudsen diffusion of the gaseous phase, thermal diffusion and sorption as local processes in the porous desiccant layer-have been adopted to support numerical simulations of the behaviour of desiccant and enthalpy wheels [53-56]. Some of the adopted assumptions [56] were: (i) the channel wall was made of a composite material, which is assumed to be an uniform mixture of substratum and desiccant materials;

(ii) the mass fraction of desiccant in the porous medium was taken as thrice the mass fraction of substratum;

(iii) the adsorption heat and the volume fraction of the gaseous phase inside the porous medium were both constant and uniform.

It is recognized the importance of validating the numerical results by comparison with experimental data. The extensive bibliographic research referred above shows a lack of information for the complete characterization of the desiccant media as required for the validation of detailed models. In some cases, the degree of accuracy of the measured results is not included and, in other works, a poor degree of accuracy is reported. A difference of about 10\% was obtained in [9] between numerical and experimental results for the behaviour of a desiccant granular bed, which is attributed to inaccuracies in the measurements and in the adopted correlations. Moreover, the experimental exhaustive research of [40] on the behaviour of a desiccant wheel showed significant mass and energy imbalances between the regeneration and the process air streams.

In the present work, the numerical modelling of the physical behaviour of a layer of a desiccant composite is addressed, considering the complete set of governing equations for the local adsorption, heat conduction and mass diffusion within the porous medium. The dependence of the thermodynamic properties, of the diffusion coefficients and of the volume fraction of the gaseous phase on the local primary variables (temperature, adsorbed water content and vapour content) is also considered. It is also supposed that the desiccant layer belongs to the channel wall of a compact exchanger, which is crossed by a moist air-vapour flow. The hypothesis of one-dimensionality assumed in this study - a plane and short element of the desiccant layer-is mainly intended to better identify the effects to 
be analysed, namely the importance of neglecting the internal diffusive resistances.

\section{Mathematical modelling}

\subsection{Physical model and simplifications}

The physical model is schematically represented in Fig. 1, together with the boundary conditions considered.

The present study is focussed on the assessment of the internal resistances of the porous medium in the cross direction. For this purpose, it is of no interest to consider the variation of the flow properties in the streamwise direction. Therefore the physical domain is reduced to an element of the channel wall, which is considered as a homogeneous desiccant medium, having the properties of silica-gel and an infinitesimal length in the flow direction. The heat and mass transfer phenomena inside the porous medium are considered only in the $y$ direction.

Inside the porous medium, two phases of water (vapour and adsorbed water) coexist in an equilibrium state, which is characterized by the water vapour-silica gel sorption isotherm. Due to the small dimension of the silica gel pores, only two mechanisms of mass transport are considered: surface diffusion of adsorbed water and Knudsen diffusion of water vapour [7]. The mass transport of dry air inside the pores is also neglected and the total pressure is assumed to be constant and uniform.

At the interface between the airflow and the desiccant layer, transfer of water vapour and of heat occurs. The upper face of the desiccant layer is located at the symmetry plane relatively to an adjacent channel, and consequently is treated as an adiabatic and impermeable boundary.

The air stream in contact with the infinitesimal-length wall element is treated as a well mixed flow (bulk flow), characterised by constant and uniform properties (pressure, temperature and vapour content), thus dispensing the need of solving any conservation equation in the flow domain.

\subsection{Model equations, coefficients and properties}

The governing equations can be mathematically deduced from appropriate balances applied to an infinitesimal control

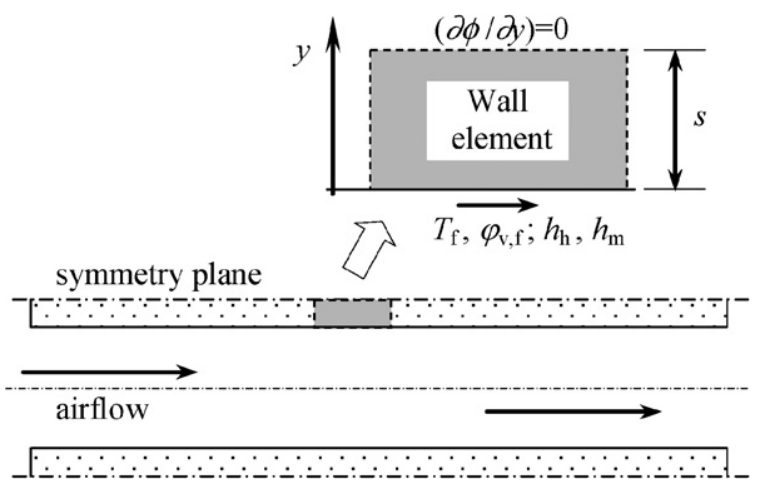

Fig. 1. Schematic representation of the plane airflow channel and of the calculation domain — a wall element—with the corresponding boundary conditions. volume of the desiccant porous medium, leading to the following partial differential equations:

- mass conservation of water vapour:

$$
\frac{\partial\left(\rho_{\mathrm{gv}}^{*} \varphi_{\mathrm{v}}\right)}{\partial t}=\frac{\partial}{\partial y}\left(\frac{D_{\mathrm{K}, \text { eff }}}{\varepsilon_{\mathrm{gv}}} \cdot \frac{\partial\left(\rho_{\mathrm{gv}}^{*} \varphi_{\mathrm{v}}\right)}{\partial y}\right)-S_{\mathrm{v}-\ell}
$$

- mass conservation of adsorbed water:

$$
\frac{\partial\left(\rho_{\mathrm{d}}^{*} X_{\ell}\right)}{\partial t}=\frac{\partial}{\partial y}\left(D_{\mathrm{s}, \mathrm{eff}} \frac{\partial\left(\rho_{\mathrm{d}}^{*} X_{\ell}\right)}{\partial y}\right)+S_{\mathrm{v}-\ell}
$$

- energy conservation in the porous medium (gas mixture, adsorbed water and solid):

$$
\frac{\partial}{\partial t}\left(\rho_{\mathrm{d}}^{*} \cdot c_{\mathrm{p}, \mathrm{p}} \cdot T\right)=\frac{\partial}{\partial y}\left(\lambda_{\mathrm{p}} \frac{\partial T}{\partial y}\right)+S_{\mathrm{ads}}
$$

Under the assumption of local thermodynamic equilibrium, only one of the above mass conservation equations must be solved. Dropping equation (1), the local value of the vapour mass fraction $\varphi_{\mathrm{v}}$ is specified as the equilibrium value $\varphi_{\mathrm{v}, \text { eq }}$, obtained from the sorption isotherm as a function of the local values of $T$ and $X_{\ell}$ [6]. Consequently, the source-term $S_{\mathrm{v}-\ell}$ representing the adsorption rate per unit volume of the porous medium is expressed by:

$S_{\mathrm{V}-\ell}=\frac{\partial}{\partial y}\left(\frac{D_{\mathrm{K}, \mathrm{eff}}}{\varepsilon_{\mathrm{gv}}} \cdot \frac{\partial\left(\rho_{\mathrm{gv}}^{*} \varphi_{\mathrm{V}}\right)}{\partial y}\right)-\frac{\partial\left(\rho_{\mathrm{gv}}^{*} \varphi_{\mathrm{v}}\right)}{\partial t}$

The energy equation (3) is written in a classical form, in terms of temperature as the primary dependent variable. From the mathematical derivation of that equation, the following expression results:

$$
\begin{aligned}
S_{\mathrm{ads}}= & \rho_{\mathrm{d}}^{*} \frac{\partial\left(X_{\ell} h_{\mathrm{w}}^{\prime}\right)}{\partial t}+\frac{\partial}{\partial y}\left(D_{\mathrm{s}, \mathrm{eff}} \frac{\partial\left(\rho_{\mathrm{d}}^{*} X_{\ell}\right)}{\partial y} h_{\ell}^{\prime}\right) \\
& +\frac{\partial}{\partial y}\left(\frac{D_{\mathrm{K}, \mathrm{eff}}}{\varepsilon_{\mathrm{gv}}} \cdot \frac{\partial\left(\rho_{\mathrm{gv}}^{*} \varphi_{\mathrm{v}}\right)}{\partial y} h_{\mathrm{v}}\right)-\frac{\partial\left(\varphi_{\mathrm{v}} \rho_{\mathrm{gv}}^{*} h_{\mathrm{fg}}\right)}{\partial t}
\end{aligned}
$$

However, this term is usually taken as $[53,55,56]$ :

$S_{\mathrm{ads}}=S_{\mathrm{v}-\ell} \cdot h_{\mathrm{ads}}$

Exploratory calculations showed that expressions (5a) and (5b) led both to practically the same results.

The specific enthalpy of the water vapour is given by

$h_{\mathrm{v}}=c_{\mathrm{p}, \mathrm{v}} T+h_{\mathrm{fg}}$

and that of the adsorbed water is given by

$h_{\ell}^{\prime}=h_{\mathrm{v}}-h_{\mathrm{ads}}$

or, by other means:

$h_{\ell}^{\prime}=h_{\ell}-h_{\mathrm{w}}^{\prime}$

where $h_{\mathrm{ads}}$ is the heat of adsorption and $h_{\mathrm{w}}^{\prime}$ is the heat of wetting.

The instantaneous volume fraction $\varepsilon_{\mathrm{gv}}$ is the ratio between the instantaneous volume occupied by the air-vapour mixture in the pores and the total volume of the solid porous medium, being correlated with the local content of adsorbed water. 
The effective diffusivity associated with Knudsen diffusion in a porous desiccant medium may be written as [6]:

$D_{\mathrm{K}, \text { eff }}=97 r_{\mathrm{gv}} \sqrt{\frac{T+273.15}{R_{\mathrm{v}}}} \frac{\varepsilon_{\mathrm{gv}}}{\tau_{\mathrm{gv}}}$

The effective diffusivity associated to the surface diffusion of adsorbed water $D_{\mathrm{s} \text {,eff }}$ in a porous desiccant medium is directly influenced by the path tortuosity $\tau_{\ell}$ and depends on the pair adsorbate-adsorbent. In the present work, the following expression was used [6]:

$D_{\mathrm{s}, \mathrm{eff}}=\frac{D_{\mathrm{s} 0}}{\tau_{\ell}} \cdot \exp \left(\frac{-4.5 \times 10^{-4} h_{\mathrm{ads}}}{b R_{\mathrm{v}}(T+273.15)}\right)$

where $b$ depends on the type of adsorption bond and $D_{\mathrm{s} 0}$ is a constant that depends on the adsorbent.

The effective thermal conductivity of the porous medium $\lambda_{\mathrm{p}}$ is difficult to predict accurately due to the coupled transfer phenomena. An average value is used according to the conductivity and mass fraction of each component phase. A similar procedure is used regarding the specific heat of the porous medium.

Finally, for the graphical representation of the results, the moisture content of the air-vapour mixture $w_{\mathrm{v}}$ (mass fraction of vapour on dry basis) is calculated from the vapour mass fraction $\varphi_{\mathrm{v}}$ through

$w_{\mathrm{v}}=\varphi_{\mathrm{v}} /\left(1-\varphi_{\mathrm{v}}\right)$

\subsection{Boundary conditions}

The upper and the two lateral faces of the wall element are considered adiabatic, as well as impermeable to both water phases (cf. Fig. 1). According to the low-mass-transfer rate theory [57], the mass and heat fluxes evaluated on the gas side of the interface are

$j_{\mathrm{m}}=h_{\mathrm{m}} \cdot \rho_{\mathrm{f}}\left(\varphi_{\mathrm{v}, \mathrm{f}}-\varphi_{\mathrm{v}, \mathrm{i}}\right)$

and

$j_{\mathrm{h}}=h_{\mathrm{h}}\left(T_{\mathrm{f}}-T_{\mathrm{i}}\right)$

respectively, where $\varphi_{\mathrm{v}, \mathrm{i}}$ and $T_{\mathrm{i}}$ are instantaneous values at the interface and $\varphi_{\mathrm{v}, \mathrm{f}}$ and $T_{\mathrm{f}}$ are instantaneous bulk flow values. The convection heat and mass transfer coefficients are taken from the values of the Nusselt and the Sherwood numbers for the fully developed laminar regime of an internal channel flow, which are related by the well-known Chilton-Colburn analogy:

$S h=N u \cdot L e^{-1 / 3}$

the Lewis number being estimated from its definition:

$L e=\lambda_{\mathrm{f}} /\left(\rho_{\mathrm{f}} c_{\mathrm{p}, \mathrm{f}} D_{\mathrm{f}}\right)$

The convection coefficients are then obtained by the expressions:

$h_{\mathrm{h}}=N u \cdot \lambda_{\mathrm{f}} / d_{\mathrm{hyd}}$

and

$h_{\mathrm{m}}=S h \cdot D_{\mathrm{f}} / d_{\text {hyd }}$
In a real channel the convection coefficients depend on the flow regime, the channel geometry and on the distance from the channel inlet. The interface fluxes calculated through Eqs. (11) and (12) are positive in the $y$ direction, i.e., when entering the wall element (cf. Fig. 1).

At the interface with the airflow, the following surface balances can be written:

$$
\begin{aligned}
& {\left[-\frac{D_{\mathrm{K}, \mathrm{eff}}}{\varepsilon_{\mathrm{gv}}} \cdot \frac{\partial\left(\rho_{\mathrm{gv}}^{*} \varphi_{\mathrm{v}}\right)}{\partial y}-D_{\mathrm{s}, \mathrm{eff}} \frac{\partial\left(\rho_{\mathrm{d}}^{*} X_{\ell}\right)}{\partial y}\right]_{y=0^{+}}} \\
& =h_{\mathrm{m}} \cdot \rho_{\mathrm{f}}\left(\varphi_{\mathrm{v}, \mathrm{f}}-\varphi_{\mathrm{v}, \mathrm{i}}\right)
\end{aligned}
$$

and

$$
\begin{aligned}
& {\left[-\frac{D_{\mathrm{K}, \mathrm{eff}}}{\varepsilon_{\mathrm{gv}}} \cdot \frac{\partial\left(\rho_{\mathrm{gv}}^{*} \varphi_{\mathrm{v}}\right)}{\partial y} h_{\mathrm{v}}-D_{\mathrm{s}, \mathrm{eff}} \frac{\partial\left(\rho_{\mathrm{d}}^{*} X_{\ell}\right)}{\partial y} h_{\ell}^{\prime}-\lambda_{\mathrm{p}} \frac{\partial T}{\partial y}\right]_{y=0^{+}}} \\
& =h_{\mathrm{h}}\left(T_{\mathrm{f}}-T_{\mathrm{i}}\right)+h_{\mathrm{m}} \cdot \rho_{\mathrm{f}}\left(\varphi_{\mathrm{v}, \mathrm{f}}-\varphi_{\mathrm{v}, \mathrm{i}}\right) \cdot h_{\mathrm{v}, \mathrm{i}}
\end{aligned}
$$

\subsection{Numerical modelling}

The detailed model described above will be hereafter taken as the reference or standard model. The partial differential equations (1)-(3) are discretized using the finite volume method [58] and solved through the tri-diagonal matrix algorithm (TDMA). An iterative procedure is performed in each time step, in order to handle the strong coupling between the governing equations and the non-linearities implied by the changing properties. With appropriate control parameters, the resulting numerical model showed a rather stable and robust behaviour along the calculation procedure.

The calculation domain is divided into control-volumes, forming a Cartesian and non-uniform grid, which is gradually expanded from the solid-flow interface towards the adiabatic/impermeable upper surface. A very short distance from the first inner grid point to the interface is imposed (0.5$1 \mu \mathrm{m}$ ), thus ensuring an accurate numerical representation of the boundary conditions expressed by Eqs. (11) and (12). These boundary conditions are introduced via the corresponding source-terms in the discretization equations [58]. Since the present study is focused on the assessment of the crossdirection resistances of the porous medium, the model is assumed one-dimensional and only one column of nodes is solved.

The time discretization consists of a step-by-step evolution, each time interval being automatically generated along the numerical simulation of the transient process. Basically, the sharper is the time evolution of the dependent variables, the shorter are the time steps imposed, and conversely. This generation algorithm guarantees a suitable representation of the transient evolutions, while minimizing the computing time needed to simulate a complete adsorption/desorption process until the steady-state.

Two simplifying approaches based on the lumped-capacitance method are numerically investigated. One corresponds to the theoretical analysis of the system neglecting the internal resistances to the heat and mass diffusion (approach A- "Null Res.”). This global lumped-capacitance approach is achieved by specifying great enough values to all diffusion coefficients 
$\left(D_{\mathrm{K}, \text { eff }}, D_{\mathrm{s}, \text { eff }}\right.$, and $\left.\lambda_{\mathrm{p}}\right)$. The other approach (B-"Null Thermal Res.") corresponds to the thermal lumped-capacitance method and it is implemented by specifying a great enough value to the thermal conductivity $\lambda_{p}$ of the medium.

\section{Results and discussion}

The use of dimensional analysis in the present situation is difficult, due to the strong variations of some parameters along the transient process and, on the other hand, to the complexity inherent to the coupled phenomena involved.

Starting from a given initial state, the response of the desiccant wall to a step change of the airflow conditions is simulated until global equilibrium is achieved. Table 1 summarizes the input data for the calculations, namely the state of the airflow and the initial conditions of the desiccant wall.

The value 2.45 was assigned to the Nusselt number corresponding to heat convection between a uniform temperature wall and a fully-developed laminar flow inside a corrugate sinusoidal-type channel of a compact exchanger [25]. The channel cross-section area was $4.5 \mathrm{~mm}^{2}$, with an internal perimeter of $10.6 \mathrm{~mm}$ and a hydraulic diameter of $1.69 \mathrm{~mm}$, approximately.

Runs were conducted covering a wide range of values of the layer thickness $(0.01 \mathrm{~mm}$ to $5 \mathrm{~mm})$ in order to study the validity of neglecting internal thermal and mass resistances (approach A — "Null Res.") and only the thermal resistance (approach B"Null Thermal Res.").

The fluid properties of the binary air-vapour mixture depend on the primary variables $T$ and $\varphi_{\mathrm{v}}$. Appropriate $\varphi_{\mathrm{v}}$-weighted functions were developed that take into account the individual dry-air and water-vapour properties available from thermodynamic tables [59]. The properties of the desiccant medium are referred to silica gel RD [6].

\subsection{Tests for grid and time-step dependence}

Exploratory calculations were made for the adsorption case referred in Table 1 and a wall-thickness of $5 \mathrm{~mm}$, in order to analyse the dependence of the results on the space and time discretization. It was concluded that no more that 10 nodes in the $y$ direction were needed to guarantee grid-independent solutions. All subsequent calculations were then performed with a single column of 10 control-volumes. On the other hand, with the procedure described in Section 2.4, the transient solutions showed very little dependence on the size and variation of the

Table 1

Airflow and initial conditions of the desiccant wall for both the adsorption and desorption processes simulated

\begin{tabular}{lll}
\hline & Adsorption & Desorption \\
\hline$T_{\mathrm{f}}\left({ }^{\circ} \mathrm{C}\right)$ & 30 & 100 \\
$w_{\mathrm{v}, \mathrm{f}}\left(\mathrm{kg} \mathrm{kg}^{-1}\right)$ & 0.01 & 0.01 \\
$p(\mathrm{~Pa})$ & 101325 & 101325 \\
$T_{0}\left({ }^{\circ} \mathrm{C}\right)$ & 100 & 30 \\
$X_{\ell, 0}\left(\mathrm{~kg} \mathrm{~kg}^{-1}\right)$ & 0.0126 & 0.2363 \\
\hline
\end{tabular}

time-interval, provided that a sufficiently short period $(0.5 \mathrm{~s}$, typically) is taken for the first 2 or 3 time-steps.

\subsection{Significance of the internal resistances}

A particular adsorption case was selected for the detailed analysis of the transient evolutions of the variables inside a desiccant layer with $1 \mathrm{~mm}$ of thickness. Time-evolving profiles are shown in Figs. 2(a)-(c) as calculated with the "normal" internal resistances (i.e., using the "standard" model, as described in Section 2). It is seen that the temperature field presents small gradients, meaning that the internal resistance to heat diffusion

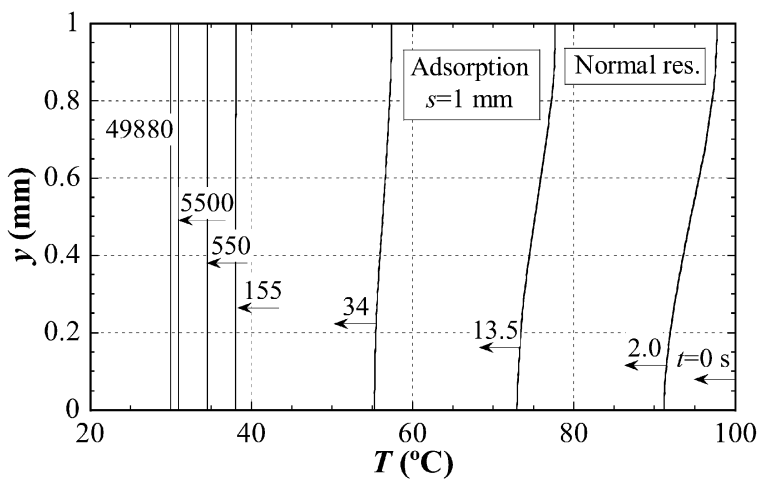

(a)

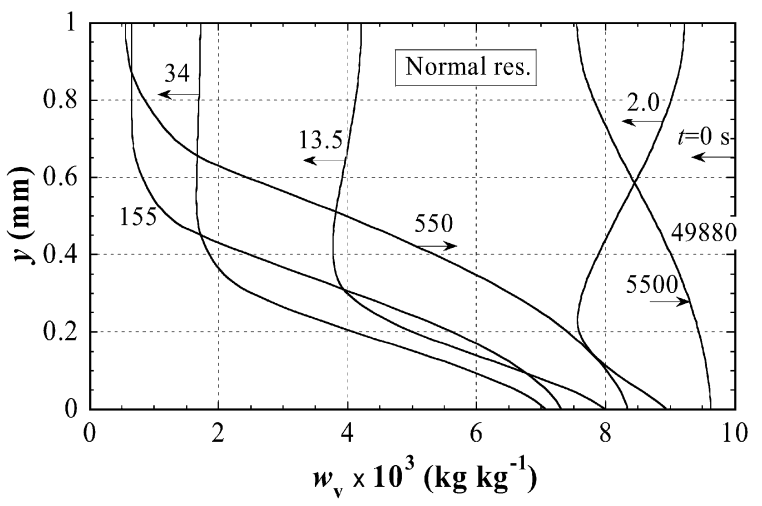

(b)

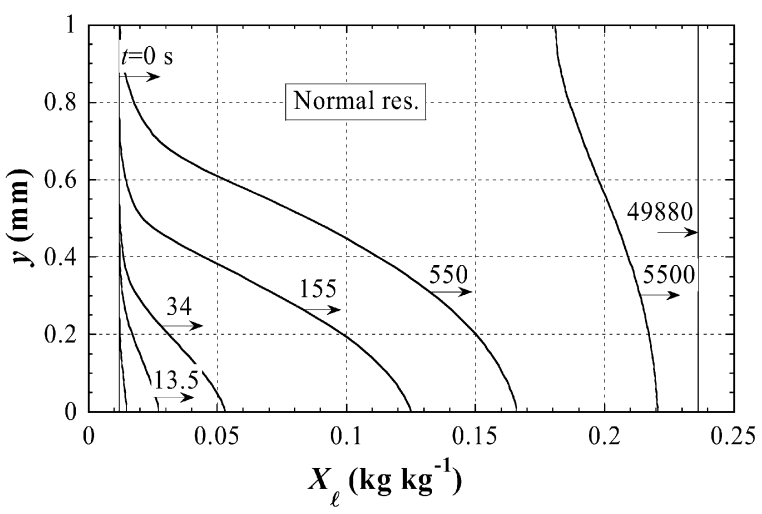

(c)

Fig. 2. Time-varying profiles of the dependent variables along the adsorption process in a desiccant layer of $s=1 \mathrm{~mm}$, considering the "normal" internal resistances: (a) temperature $T$; (b) vapour content $w_{\mathrm{v}}$; (c) content of adsorbed water $X_{\ell}$. 
is almost insignificant, contrarily to those restricting the mass diffusion.

The same case was simulated using two different simplified versions of the model, taking thickness values in the range of 0.01 to $5 \mathrm{~mm}$ : one cancelling both thermal and mass resistances inside the desiccant wall (approach A), the other cancelling only the thermal resistance (approach B). The diagrams in Figs. 3 and 4 show the time evolutions of a set of relevant variables for the adsorption and the desorption processes referred in Table 1, respectively. It can be observed that the results of approach A (dashed lines) show a good agreement with those of the detailed model (full lines) only for very thin desiccant layers $(s \leqslant 0.01 \mathrm{~mm})$, and that they diverge as the desiccant layer thickness increases. This indicates that significant inaccuracies may result when the internal resistances to both heat and mass diffusion are neglected. In particular, according to Figs. 3(c) and (d) and Figs. 4(c) and (d), this hypothesis may lead to unrealistic estimation of the convection fluxes at the interface. It can be observed that the results of approach B (dashed-lines with marker) agree well with the detailed model for all studied wall thicknesses, except for $s=5 \mathrm{~mm}$. In all cases, no significant deviation is observed in the evolutions of the adsorbed water content, as can be seen in Figs. 3(b) and 4(b).

To better assess the deviations of the results with each of the approaches A and B relatively to the detailed modelling, a global indicator is defined, on the basis of the interfacial heat and mass fluxes:

$\Delta \varepsilon=\frac{\int_{0}^{t_{1}}\left(j_{\mathrm{A}, \mathrm{B}}-j_{\text {norm }}\right) \mathrm{d} t}{\int_{0}^{t_{1}} j_{\text {norm }} \mathrm{d} t}$

where $t_{1}$ is chosen as the time needed in each case for the variable $\widetilde{X}_{\ell}$ to reach $90 \%$ of its maximum variation, when predicted by the detailed model (index 'norm'). Fig. 5 allows to conclude that the global lumped-capacitance model is reasonably valid for $s \leqslant 0.1 \mathrm{~mm}(\Delta \varepsilon \leqslant 4 \%)$, while the thermal lumpedcapacitance approach is valid for all studied values of the wall thickness.

In a general way, the transient sorption process depends on the convective heat and mass transfer coefficients and, mainly, on the total mass of the wall and on the coefficients for the internal diffusion of heat and mass, which exhibit opposed variations along the adsorption and the desorption processes. This is the reason for the faster evolution of the desorption process, as it can be inferred from the comparison of Figs. 4(a) and (b).

\subsection{Final remarks}

The lumped capacitance method can be often used to solve problems of transient heat conduction in solids. The assessment of its validity is based on the magnitude of the Biot number:

$B i_{\mathrm{h}}=\frac{h_{\mathrm{h}} s}{\lambda_{\mathrm{p}}}$

Likewise, in transient mass diffusion problems inside a porous wall with no phase change, a Biot number for mass transfer can be used:

$B i_{\mathrm{m}}=\frac{h_{\mathrm{m}} s}{D_{\mathrm{p}}}$

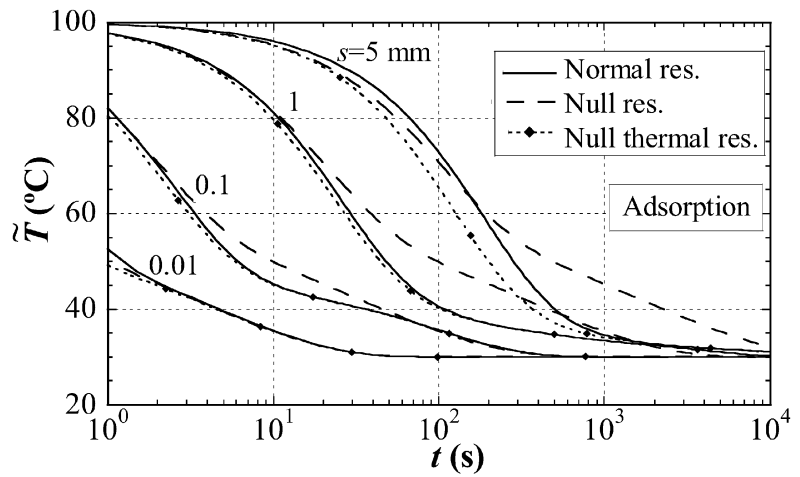

(a)

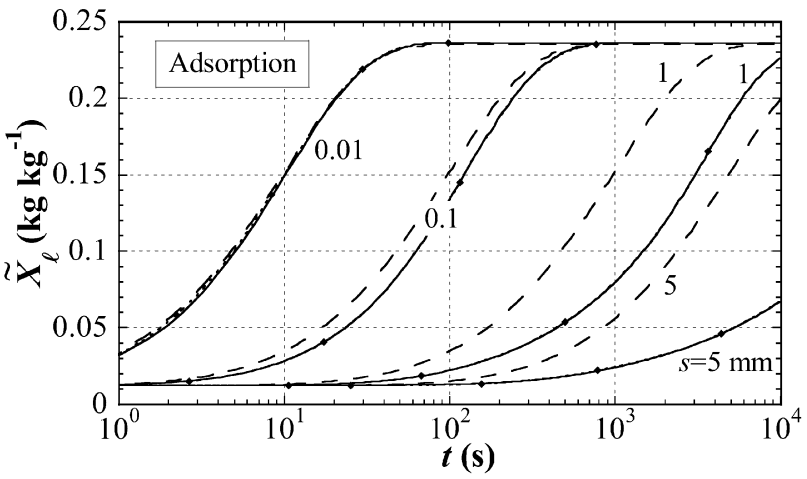

(b)

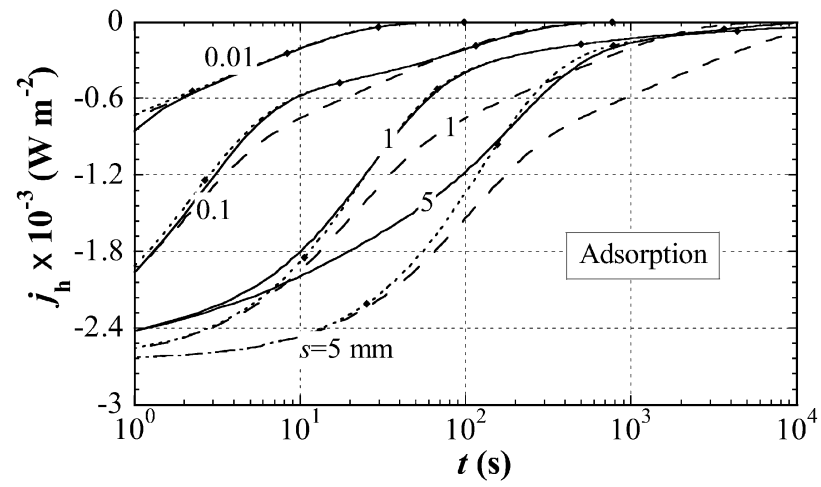

(c)

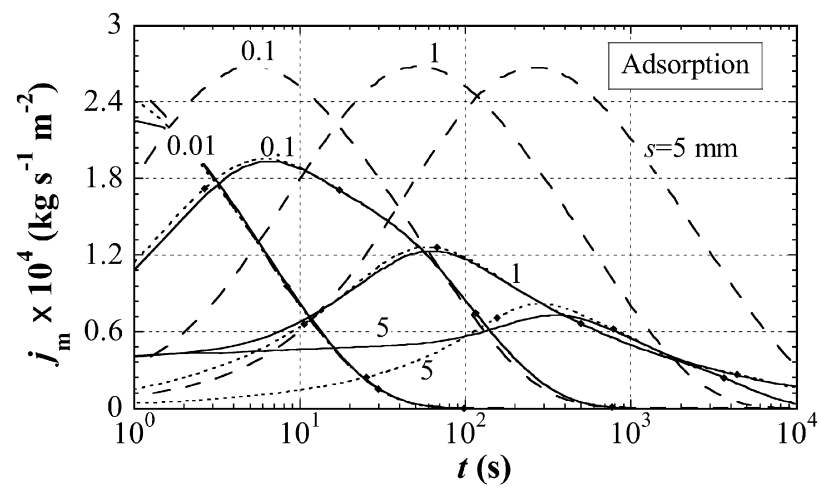

(d)

Fig. 3. Effect of imposing internally null mass and thermal resistances and null thermal resistance on the predicted evolution of the adsorption process ( $\mathrm{v}$. Table 1), by comparison of the time variations of: the space-averaged (a) temperature and (b) content of adsorbed water; the (c) heat and (d) mass fluxes at the interface. $((-)$ normal, $(---)$ null thermal and mass and $(-\downarrow)$ null thermal resistances.) 


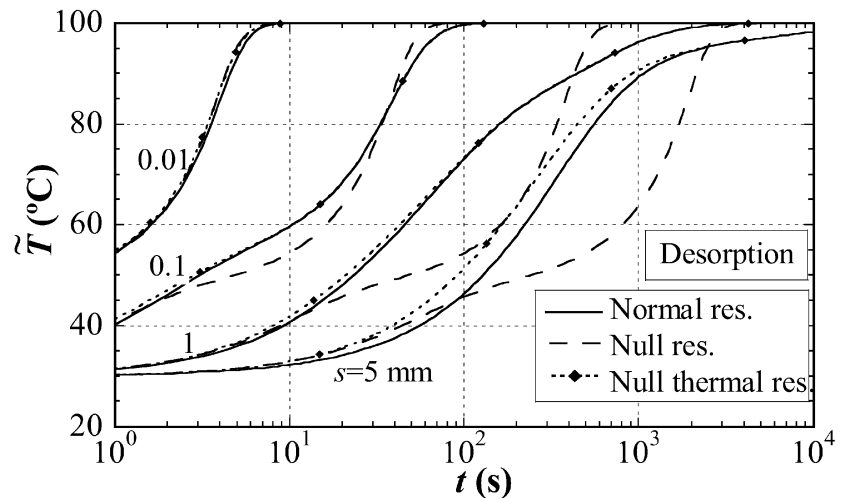

(a)

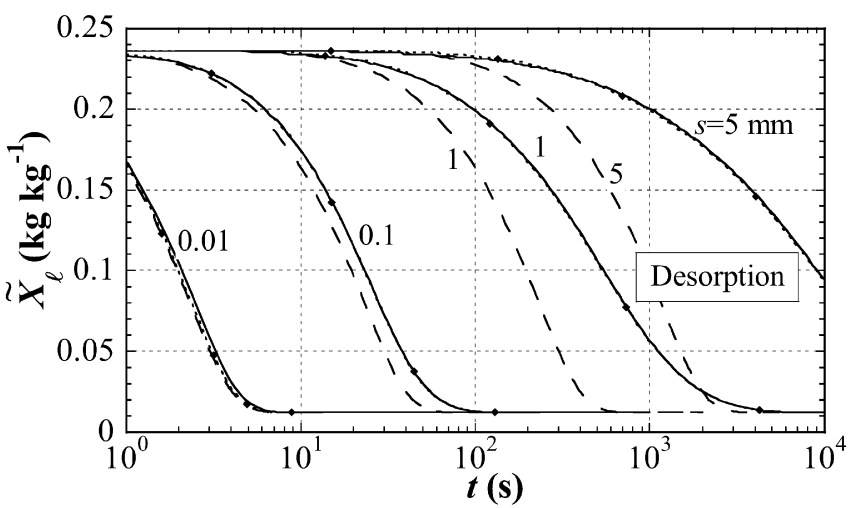

(b)

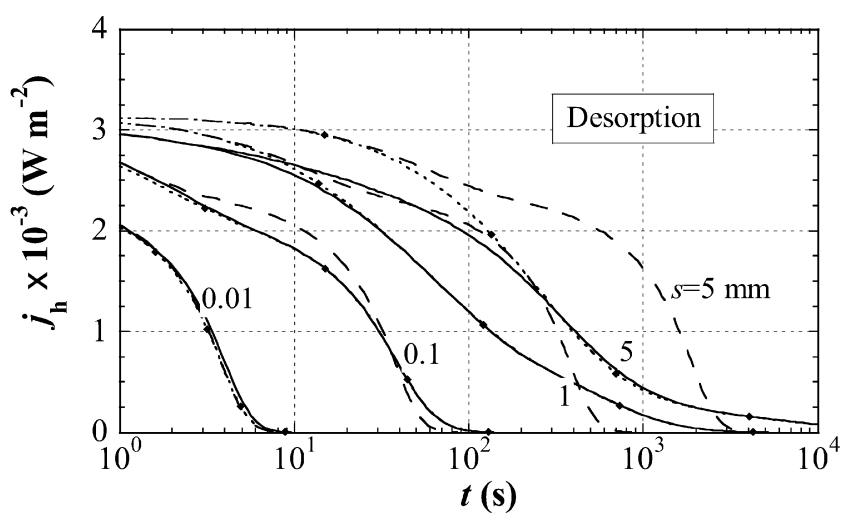

(c)

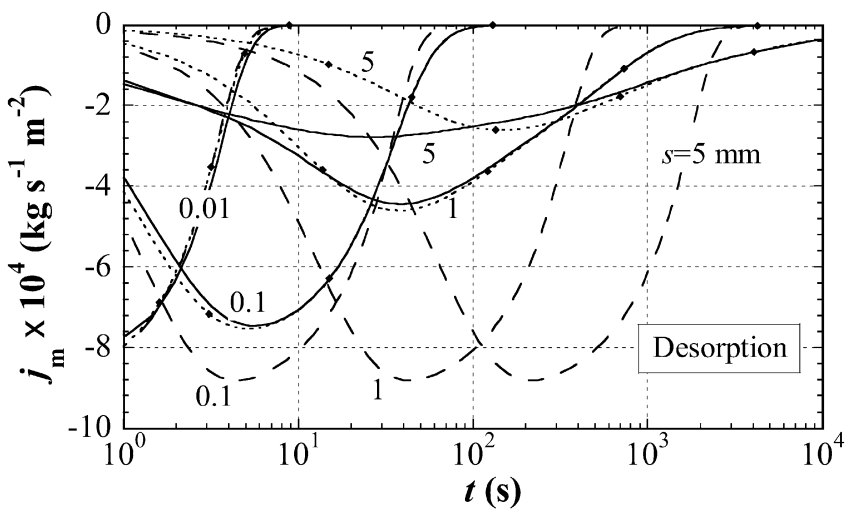

(d)

Fig. 4. Effect of the null thermal and mass resistances and null thermal resistance assumptions on the predicted time evolution of the desorption process (v. Table 1): (a)-(d) as in Fig. 5.

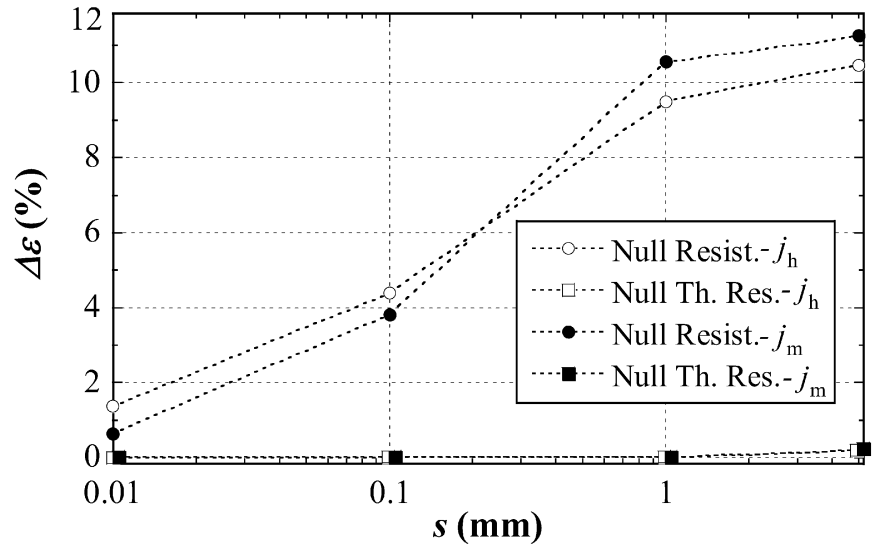

Fig. 5. Deviation of the evolutions of the convective fluxes of the null resistances and of null thermal resistance approaches relatively to the predicted evolutions of the adsorption process with normal resistances.

where $D_{\mathrm{p}}$ is a coefficient of mass diffusion within the porous medium and $s$ is the half-thickness of the wall. In the present case, the heat and mass fluxes convected to the surface split into two terms within the porous medium, due to the phase change imposed by the sorption phenomenon, as shown by the balance equations (17) and (18). These may be rewritten as:

$h_{\mathrm{m}}\left(C_{\mathrm{v}, \mathrm{f}}-C_{\mathrm{v}, \mathrm{i}}\right)=\left[-D_{\mathrm{K}, \mathrm{eff}} \cdot \frac{\partial C_{\mathrm{v}}}{\partial y}-D_{\mathrm{s}, \mathrm{eff}} \frac{\partial C_{\ell}}{\partial y}\right]_{y=0^{+}}$

and

$h_{\mathrm{h}}\left(T_{\mathrm{f}}-T_{\mathrm{i}}\right)=\left[-j_{\mathrm{ads}} h_{\mathrm{ads}}-\lambda_{\mathrm{p}} \frac{\partial T}{\partial y}\right]_{y=0^{+}}$

where

$j_{\text {ads }}=-D_{\text {s,eff }} \frac{\partial C_{\ell}}{\partial y}$

represents the adsorption rate per unit area of the interface, after the mass balance expressed by Eq. (22). The resulting normalized forms of the mass and energy balances at the interface are, respectively:

$\left[-\frac{1}{B i_{\mathrm{K}}} \cdot \frac{\partial C_{\mathrm{v}}^{+}}{\partial y^{+}}-\frac{1}{B i_{\mathrm{s}}} \cdot \frac{\partial C_{\ell}^{+}}{\partial y^{+}}\right]_{y=0^{+}}=1$

and

$\left[-\frac{\Phi_{\mathrm{h}, \text { ads }}^{+}}{B i_{\mathrm{S}}} \frac{\partial C_{\ell}^{+}}{\partial y^{+}}-\frac{1}{B i_{\mathrm{h}}} \frac{\partial T^{+}}{\partial y^{+}}\right]_{y=0^{+}}=1$

where the dimensionless mass concentrations are $C_{\mathrm{v}}^{+}=C_{\mathrm{v}} /$ $\left(C_{\mathrm{v}, \mathrm{f}}-C_{\mathrm{v}, \mathrm{i}}\right)$ and $C_{\ell}^{+}=C_{\ell} /\left(C_{\mathrm{v}, \mathrm{f}}-C_{\mathrm{v}, \mathrm{i}}\right)$ and three Biot numbers appear: one for heat transfer with the usual definition, $B i_{\mathrm{h}}=h_{\mathrm{h}} s / \lambda_{\mathrm{p}}$, and two Biot numbers for mass transfer, re-

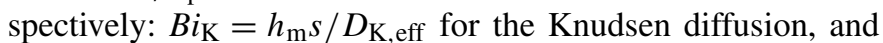
$B i_{\mathrm{s}}=h_{\mathrm{m}} s / D_{\mathrm{s}, \text { eff }}$ for the surface diffusion. The parameter

$\Phi_{\mathrm{h}, \mathrm{ads}}^{+}=\frac{h_{\mathrm{m}}\left(C_{\mathrm{v}, \mathrm{f}}-C_{\mathrm{v}, \mathrm{i}}\right) h_{\mathrm{ads}}}{h_{\mathrm{h}}\left(T_{\mathrm{i}}-T_{\mathrm{f}}\right)}$

represents the ratio between the heat released in the phase change of the vapour flux convected to the interface, if the phase 


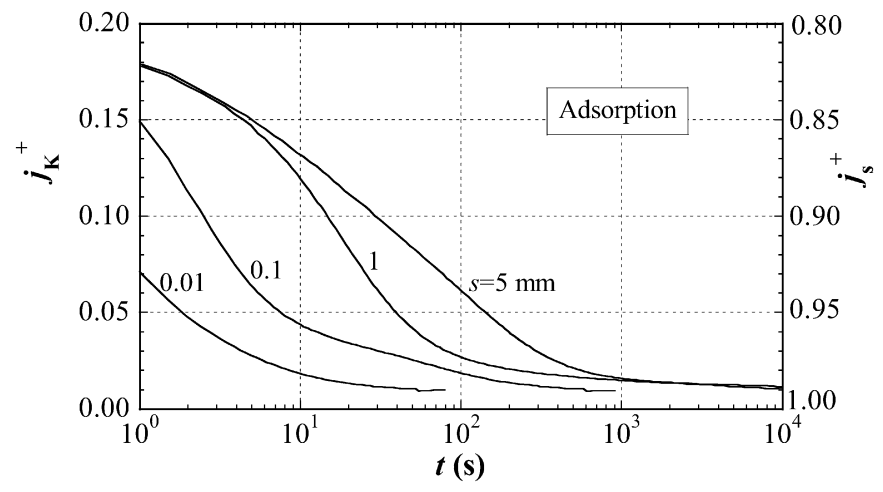

Fig. 6. Dimensionless mass fluxes by Knudsen and by surface diffusion at the interface defined as $j_{\mathrm{K}}^{+}=-\left(1 / B i_{\mathrm{K}}\right) \cdot\left(\partial C_{\mathrm{V}}^{+} / \partial y^{+}\right)$and $j_{\mathrm{s}}^{+}=$ $-\left(1 / B i_{\mathrm{S}}\right) \cdot\left(\partial C_{\ell}^{+} / \partial y^{+}\right)$, respectively.

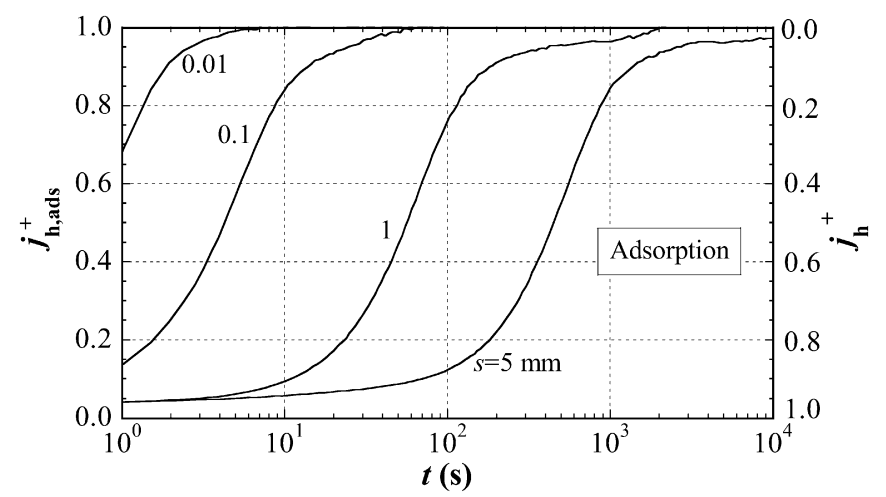

Fig. 7. Dimensionless heat generation/consumption rate per unit area of the interface and heat conduction flux, defined by $j_{\mathrm{h}, \text { ads }}^{+}=$ $-\left(\Phi_{\mathrm{h}, \text { ads }}^{+} / B i_{\mathrm{s}}\right) \cdot\left(\partial C_{\ell}^{+} / \partial y^{+}\right)$and $j_{\mathrm{h}}^{+}=-\left(1 / B i_{\mathrm{h}}\right) \cdot\left(\partial T^{+} / \partial y^{+}\right)$, respectively.

change were completely achieved, and the convection heat flux. It may also be expressed as:

$\Phi_{\mathrm{h}, \mathrm{ads}}^{+}=\frac{h_{\mathrm{ads}} D_{\mathrm{f}}\left(C_{\mathrm{v}, \mathrm{f}}-C_{\mathrm{v}, \mathrm{i}}\right)}{\lambda_{\mathrm{f}}\left(T_{\mathrm{i}}-T_{\mathrm{f}}\right)} L e^{-1 / 3}$

after the Chilton-Colburn analogy (cf. Eqs. (1), (15), (16)), which provides a quick assessment of its order of magnitude.

Eqs. (24) and (25) indicate that the internal gradients of temperature and of the mass concentration of both water phases are coupled. This means that the relevance of the internal gradients can not be directly assessed by a unique dimensionless parameter.

The time evolutions of the terms on the left side of Eqs. (24) and (25) are plotted in Figs. 6 and 7 for the adsorption case and different wall thicknesses. It can be seen from Fig. 6 that, after a short initial period, the contribution of Knudsen diffusion is negligible, meaning that the surface diffusion is the dominant mass transport phenomenon inside the porous medium, which is in agreement with [6]. On the other hand, Fig. 7 shows the relative importance of the two terms in Eq. (25) along the process: $j_{\mathrm{h}}^{+}$is generally more important in the beginning, while the phase change term $j_{\mathrm{h} \text {,ads }}^{+}$becomes gradually dominant.

If the assertions supported by Fig. 6 are included in Eq. (24), it can be concluded that the relevance of the internal gradients

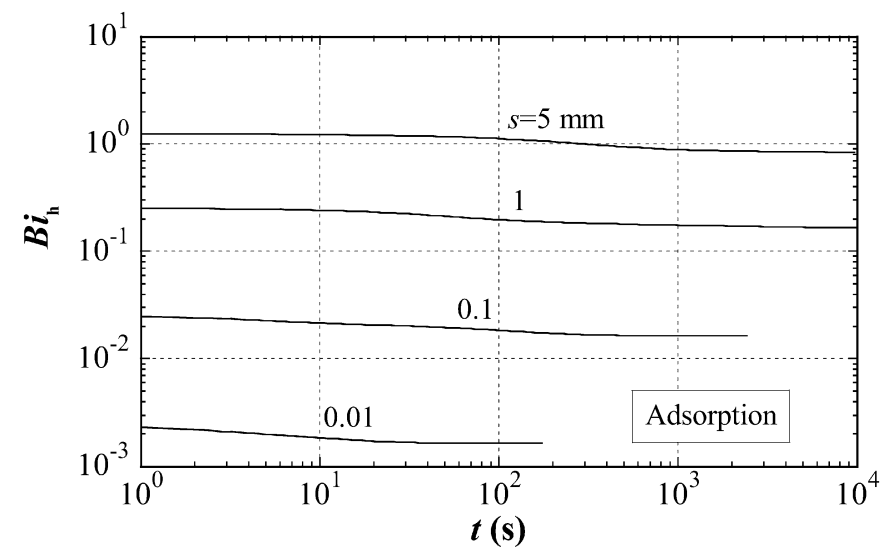

(a)

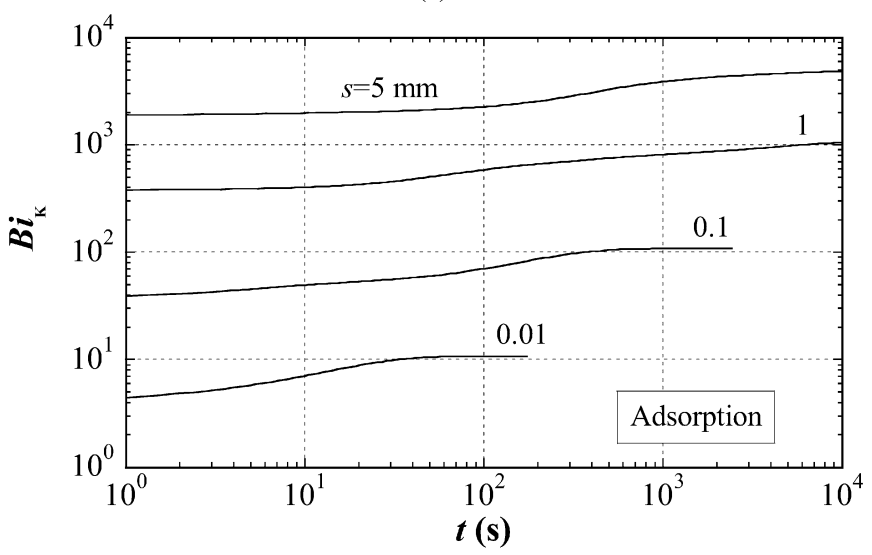

(b)

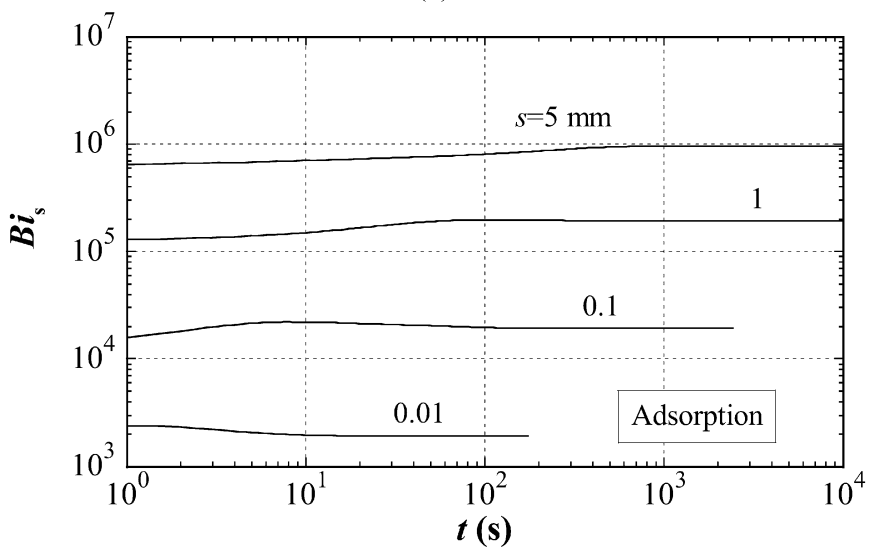

(c)

Fig. 8. Biot numbers for: (a) heat conduction, (b) Knudsen and (c) surface diffusion.

of mass concentration of adsorbed water may be directly represented by the magnitude of $B i_{\mathrm{s}}$. On the contrary, the observation of Fig. 7 together with Eq. (24) shows that both terms have importance, even at different stages of the process, the thermal gradients being affected simultaneously by $B i_{\mathrm{h}}$ and by the parameter $B i_{\mathrm{s}} / \Phi_{\mathrm{h}, \text { ads }}^{+}$. The calculated time evolutions of the three Biot numbers defined previously are plotted for the same cases in Figs. 8(a)-(c), where an obvious influence of the desiccant layer thickness can be observed. Besides, these parameters experience significant variations along the process: $B i_{\mathrm{h}}$ decreases about $30 \%$, while $B i_{\mathrm{K}}$ nearly doubles its value and $B i_{\mathrm{S}}$ increases 


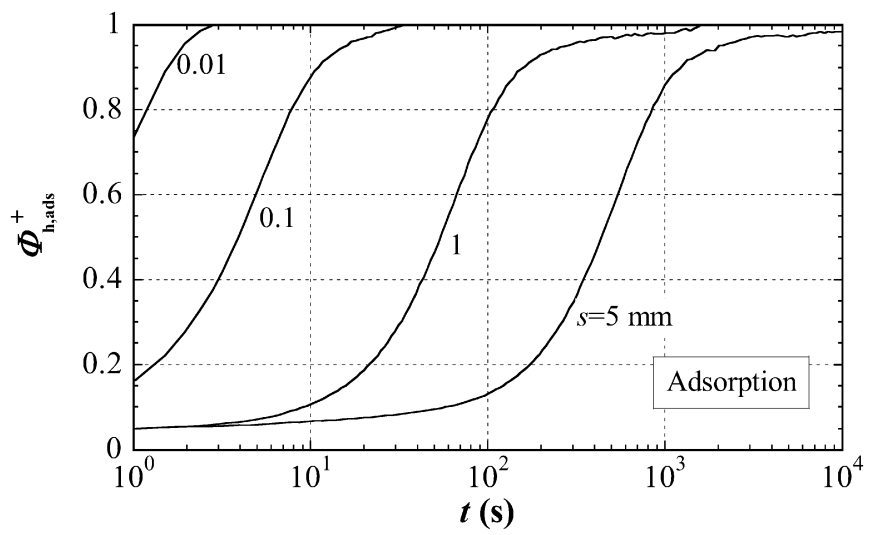

Fig. 9. Ratio between the heat released in the phase change and the convection heat flux, $\Phi_{\mathrm{h}, \text { ads }}^{+}$.

almost $50 \%$ (except for $s \leqslant 0.01 \mathrm{~mm}$, with changes of about $\pm 10 \%)$. In Fig. 9, the calculated time evolutions of the parameter $\Phi_{\mathrm{h} \text {,ads }}^{+}$are presented. It can be observed that they are very close to the evolutions obtained for the parameter $j_{\mathrm{h}, \text { ads }}^{+}$, which is in agreement with the fact that the surface diffusion is the dominant mass transport phenomenon.

The analysis of the results of Section 3.2, in particular those represented in Fig. 5, leads to the conclusion that the thermal lumped capacitance model is valid when $B i_{\mathrm{h}} \leqslant 1(s=5 \mathrm{~mm})$, approximately, and that the validity of the global lumped capacitance model is reasonable when $B i_{\mathrm{s}} \leqslant 2 \times 10^{4}$, this value being several orders of magnitude higher than the critical thermal Biot number.

\section{Conclusions}

A detailed mathematical model was formulated in order to describe the behaviour of a wall element of a compact heat and mass exchanger, like a desiccant wheel. A one-dimensional version of it was used under specific conditions, aiming to determine the validity field of the hypotheses of negligible internal resistances of the porous medium in the cross direction, which are frequently used in simplified models.

The capabilities of the model were demonstrated, namely the detailed analysis of the transient distributions of the primary variables (temperature, content of adsorbed water and water vapour content) across the desiccant layer. The time evolutions of the averaged variables, as well as the transient heat and mass fluxes at the interface, predicted by the detailed standard model were compared with those based on the hypothesis of "null" internal resistances for heat and mass diffusion (approach A) and of null thermal resistances (approach B).

From a dimensional analysis, it was possible to conclude that in a sorption process the relevance of the internal temperature and mass concentration gradients can only be assessed through the order of magnitude of a set of four dimensionless numbers, which includes at least three Biot numbers.

It was also concluded that, for the adsorption/desorption cases simulated, the heat and mass lumped capacitance assumption supporting the pseudo gas-side model is valid only for desiccant layers thinner than about $0.1 \mathrm{~mm}$, corresponding approximately to the range of $B i_{\mathrm{s}}<2 \times 10^{4}$. The use of the thermal lumped capacitance model in this kind of coupled heat and mass transfer problems appears to be reasonable when $B i_{\mathrm{h}}<1$.

In a 2-D modelling, the characteristic dimension associated to the internal diffusion phenomena occurring in the axial direction is the channel length, which is typically two or three orders of magnitude greater than the thickness of the desiccant layer. Therefore, the assumption of null resistances to diffusion in the axial direction is not applicable. In this case, an interesting hypothesis to be numerically investigated consists of assuming infinite resistance values (or, by other words, neglecting diffusion) in the streamwise direction, meaning that the internal axial gradients are only due to the convective interaction with the air flow. This will be addressed in a future work, when using the 2-D formulation of the model.

\section{References}

[1] E. Van Den Bulk, J.W. Mitchell, S.A. Klein, The use of dehumidifiers in desiccant cooling and dehumidification systems, J. Heat Transfer ASME 108 (3) (1986) 684-692.

[2] R.R. Smith, C.C. Hwang, R.S. Dougall, Modeling of a solar-assisted desiccant air conditioner for a residential building, Energy 19 (6) (1994) 679-691.

[3] M.Ö. Çarpınlıoğlu, M.Yıldırım, A methodology for the performance evaluation of an experimental desiccant cooling system, Int. Commun. Heat Mass Transfer, in press.

[4] J.J. Jurinak, J.W. Mitchell, Effect of matrix properties on the performance of a counterflow rotary dehumidifier, J. Heat Transfer ASME 106 (4) (1984) 638-645.

[5] P. Majumdar, M.K. Sarwar, Performance of a desiccant dehumidifier bed with mixed inert and desiccant materials, Energy 19 (1) (1994) 103-116.

[6] A. Pesaran, Moisture transport in silica gel particle beds, $\mathrm{PhD}$ thesis, University of California, Los Angeles, USA, 1983.

[7] A.A. Pesaran, A. Mills, Moisture transport in silica gel packed beds-I. Theoretical study, Int. J. Heat Mass Transfer 30 (6) (1987) 1037-1049.

[8] A.A. Pesaran, A. Mills, Moisture transport in silica gel packed beds-II. Experimental study, Int. J. Heat Mass Transfer 30 (6) (1987) 1051-1060.

[9] J.Y. San, G.D. Jiang, Modeling and testing of a silica gel packed bed system, Int. J. Heat Mass Transfer 37 (8) (1994) 1173-1179.

[10] Y.I. Aristov, I.V. Mezentsev, V.A. Mukhin, Investigation of the moisture exchange in a stationary adsorbent layer through which air is passed, J. Engrg. Phys. Thermophys. 78 (2) (2005) 248-255.

[11] C.J. Simonson, R.W. Besant, Heat and moisture transfer in desiccant coated rotary energy exchangers: Part I. Numerical model, HVAC\&R Res. 3 (4) (1997) 325-350.

[12] J.Y. San, Y.C. Hsu, L.J. Wu, Adsorption of toluene on activated carbon in a packed bed, Int. J. Heat Mass Transfer 41 (21) (1998) 3229-3238.

[13] H.S. Al-Sharqawi, N. Lior, Conjugate computation of transient flow and heat and mass transfer between humid air and desiccant plates and channels, Numer. Heat Transfer A-Appl. 46 (6) (2004) 525-548.

[14] J.Y. San, Heat and mass transfer in a two-dimension cross-flow regenerator with a solid conduction effect, Int. J. Heat Mass Transfer 36 (3) (1993) 633-643.

[15] C.J. Simonson, R.W. Besant, Energy wheel effectiveness: part Idevelopment of dimensionless groups, Int. J. Heat Mass Transfer 42 (12) (1999) 2161-2170.

[16] J.W. Jeong, S.A. Mumma, Practical thermal performance correlations for molecular sieve and silica gel loaded enthalpy wheels, Appl. Thermal Engrg. 25 (5-6) (2005) 719-740.

[17] I.L. Maclaine-Cross, P.J. Banks, Coupled heat and mass transfer in regenerators-prediction using an analogy with heat transfer, Int. J. Heat Mass Transfer 15 (6) (1972) 1225-1242.

[18] P.J. Banks, Coupled equilibrium heat and single adsorbate transfer in fluid flow through a porous medium-I. Characteristic potentials and specific capacity ratios, Chem. Engrg. Sci. 27 (5) (1972) 1143-1155. 
[19] E. Van Den Bulk, J.W. Mitchell, S.A. Klein, Design theory for rotary heat and mass exchangers-I. Wave analysis of rotary heat and mass exchangers with infinite transfer coefficients, Int. J. Heat Mass Transfer 28 (8) (1985) 1575-1586.

[20] E. Van Den Bulk, J.W. Mitchell, S.A. Klein, Design theory for rotary heat and mass exchangers-II. Effectiveness-number-of-transfer-units method for rotary heat and mass exchangers, Int. J. Heat Mass Transfer 28 (8) (1985) 1587-1595.

[21] W. Zheng, W.M. Worek, Numerical simulation of combined heat and mass transfer processes in a rotary dehumidifier, Numer. Heat Transfer AAppl. 23 (2) (1993) 211-232.

[22] J.Y. San, S.C. Hsiau, Effect of axial solid heat conduction and mass diffusion in a rotary heat and mass regenerator, Int. J. Heat Mass Transfer 36 (8) (1993) 2051-2059.

[23] C.C. Ni, J.Y. San, Mass diffusion in a spherical microporous particle with thermal effect and gas-side mass transfer resistance, Int. J. Heat Mass Transfer 43 (12) (2000) 2129-2139.

[24] Y.J. Dai, R.Z. Wang, H.F. Zhang, Parameter analysis to improve rotary desiccant dehumidification using a mathematical model, Int. J. Thermal Sci. 40 (4) (2001) 400-408.

[25] X.J. Zhang, Y.J. Dai, R.Z. Wang, A simulation study of heat and mass transfer in a honeycomb rotary desiccant dehumidifier, Appl. Thermal Engrg. 23 (8) (2003) 989-1003.

[26] M.N. Golubovic, W.M. Worek, Influence of elevated pressure on sorption in desiccant wheels, Numer. Heat Transfer A-Appl. 45 (9) (2004) 869886.

[27] Z. Gao, V.C. Mei, J.J. Tomlinson, Theoretical analysis of dehumidification process in a desiccant wheel, Heat Mass Transfer 41 (11) (2005) 10331042.

[28] E. Van den Bulk, S.A. Klein, A single-blow test procedure for compact heat and mass exchangers, J. Heat Transfer ASME 112 (2) (1990) $317-$ 322.

[29] D.D. Do, R.G. Rice, Validity of the parabolic profile assumption in adsorption, AIChE J. 32 (1) (1986) 149-154.

[30] E.R. Gilliland, R.F. Baddour, G.P. Perkinson, K.J. Sladek, Diffusion on surfaces. I. Effect of concentration on the diffusivity of physically adsorbed gases, Indust. Engrg. Chem. Fundam. 13 (2) (1974) 95-99.

[31] K.J. Sladek, E.R. Gilliland, R.F. Baddour, Diffusion on surfaces. II. Correlation of diffusivities of physically and chemically adsorbed species, Indust. Engrg. Chem. Fundam. 13 (2) (1974) 100-105.

[32] C.C. Ni, J.Y. San, Measurement of apparent solid-side mass diffusivity of a water vapour-silica gel system, Int. J. Heat Mass Transfer 45 (9) (2002) 1839-1847.

[33] J.Y. San, C.C. Ni, S.H. Hsu, Validity of solid-side mass diffusivity in simulation of water adsorbed by silica gel in packed beds, Int. J. Thermal Sci. 41 (1) (2002) 41-49.

[34] R. Tauscher, U. Dinglreiter, B. Durst, F. Mayinger, Transport processes in narrow channels with application to rotary exchangers, Heat Mass Transfer 35 (2) (1999) 123-131.

[35] J.L. Niu, L.Z. Zhang, Heat transfer and friction coefficients in corrugated ducts confined by sinusoidal and arc curves, Int. J. Heat Mass Transfer 45 (3) (2002) 571-578.

[36] L.Z. Zhang, J.L. Niu, A numerical study of laminar forced convection in sinusoidal ducts with arc lower boundaries under uniform wall temperature, Numer. Heat Transfer A-Appl. 40 (1) (2001) 55-72.

[37] Y.K. Chuah, P. Norton, F. Kreith, Transient mass transfer in parallel passage dehumidifiers with and without solid side resistance, J. Heat Transfer ASME 111 (4) (1989) 1038-1044.
[38] T. Kravchik, E. Korin, I. Borde, Influence of material properties and heat removal on mass and heat transfer in a solid desiccant dehumidifier, Chem. Engrg. Process. 27 (1) (1990) 19-25.

[39] E. Van den Bulck, Transient heat and mass transfer in laminar flow forced convection in ducts, Int. J. Heat Mass Transfer 34 (4/5) (1991) 1249-1258.

[40] J.M. Cejudo, R. Moreno, A. Carrillo, Physical and neural network models of a silica-gel desiccant wheel, Energy Build. 34 (8) (2002) 837-844.

[41] A. Kodama, T. Hirayama, M. Goto, T. Hirose, R.E. Critoph, The use of psychrometric charts for the optimisation of a thermal swing desiccant wheel, Appl. Thermal Engrg. 21 (16) (2001) 1657-1674.

[42] M. Beccali, F. Butera, R. Guanella, R.S. Adhikari, Simplified models for the performance evaluation of desiccant wheel dehumidification, Int. J. Energy Res. 27 (1) (2003) 17-29.

[43] S. Murali Krishna, S. Srinivasa Murthy, Experiments on silica gel rotary dehumidifier, Heat Recovery Systems \& CHP 9 (5) (1989) 467-473.

[44] A. Kodama, M. Goto, T. Hirose, T. Kuma, Experimental study of optimal operation for a honeycomb adsorber operated with thermal swing, J. Chem. Engrg. Jpn. 26 (5) (1993) 530-535.

[45] E.A. Vineyard, J.R. Sand, D.J. Durfee, Parametric analysis of variables that affect the performance of a desiccant dehumidification system, ASHRAE Trans. 106 (1) (2000).

[46] M.Ö. Çarpınlıŏ̆lu, M. Yıldırım, M. Kanoğlu, Experimental study on an open cycle desiccant cooling system, Int. J. Exergy 1 (2) (2004) 268-288.

[47] A. Kodama, W. Jin, M. Goto, T. Hirose, M. Pons, Entropic analysis of adsorption open cycles for air conditioning. Part 2: interpretation of experimental data, Int. J. Energy Res. 24 (3) (2000) 263-278.

[48] J.R. Camargo, C.D. Ebinuma, J.L. Silveira, Thermoeconomic analysis of an evaporative desiccant air conditioning system. Part 2: interpretation of experimental data, Appl. Thermal Engrg. 23 (12) (2003) 1537-1549.

[49] M. Czachorski, J. Wurm, W.M. Worek, J. Mierke, P. Brillhart, Dynamic testing of desiccant matrices and computerized evaluation of performance maps, ASHRAE Trans. 103 (Part 1) (1997) 833-840.

[50] P. Mazzei, F. Minichiello, D. Palma, Desiccant HVAC systems for commercial buildings, Appl. Thermal Engrg. 22 (5) (2002) 545-560.

[51] C.B. Beggs, S. Halliday, A theoretical evaluation of solar-powered desiccant cooling in the United, Build. Serv. Engrg. Res. Technol. 20 (3) (1999) 113-117.

[52] H.I. Henderson, J.R. Sand, An hourly building simulation tool to evaluate hybrid desiccant system configuration options, ASHRAE Trans. 109 (2) (2003) 551-564.

[53] L.A. Sphaier, W.M. Worek, Analysis of heat and mass transfer in porous sorbents used in rotary regenerators, Int. J. Heat Mass Transfer 47 (14-16) (2004) 3415-3430.

[54] P. Majumdar, Heat and mass transfer in composite pore structures for dehumidification, Sol. Energy 62 (1) (1998) 1-10.

[55] J.L. Niu, L.Z. Zhang, Effects of wall thickness on the heat and moisture transfer in desiccant wheels for air dehumidification and enthalpy recovery, Int. Commun. Heat Mass Transfer 29 (2) (2002) 255-268.

[56] L.Z. Zhang, J.L. Niu, A pre-cooling Munters environmental control desiccant cooling cycle in combination with chilled-ceiling panels, Energy 28 (3) (2003) 275-292.

[57] A.F. Mills, Heat and Mass Transfer, Irwin, 1995.

[58] S.V. Patankar, Numerical Heat Transfer and Fluid Flow, Hemisphere, McGraw-Hill, Washington, DC, 1980.

[59] Y. Çengel, Heat Transfer-A Practical Approach, McGraw-Hill, New York, 1998. 